\title{
EXCIMER LASER SCLEROSTOMY: THE IN VITRO DEVELOPMENT OF A MODIFIED OPEN MASK DELIVERY SYSTEM
}

\author{
B. D. S. ALLAN, P. P. VAN SAARLOOS, A. V. RUSSO, R. L. COOPER and I. J. CONSTABLE \\ Perth, Australia
}

\begin{abstract}
SUMMARY
The argon fluoride (ArF) excimer laser at $193 \mathrm{~nm}$ ablates the ocular tissues with a new order of precision and virtually no adjacent damage. A glaucoma filtration operation has been designed in which small-bore sclerostomies are created using the ArF excimer laser delivered through an open mask. The mask plicates the conjunctiva at the limbus prior to ablation. Removing the mask at the end of the procedure allows the conjunctiva to relax back to its original position, separating the conjunctival and scleral wounds. Formal conjunctival dissection is thus avoided. Feasibility studies in cadaver pig eyes, using a fluence per pulse of $400 \mathrm{~mJ} / \mathrm{cm}^{2}$ and a pulse repetition rate of $20 \mathrm{~Hz}$, indicate that sclerostomies of $300 \mu \mathrm{m}$ diameter can be reliably formed if an en-face air jet is built into the mask to raise the pressure in the target area, preventing aqueous flooding.
\end{abstract}

Trabeculectomy fails to maintain the intraocular pressure below $21 \mathrm{mmHg}$ in $10-20 \%$ of cases depending on the series, ${ }^{1}$ and this failure rate increases with repetition. In rabeculectomy, the factors which determine the initial filwation rate (operative dimensions and the tension of scleral flap apposition) are only notionally controlled. Tissue rauma and the subsequent wound healing response are also variable. Thus failure of filtration in a proportion of cases is difficult to avoid.

Reliability might be improved in glaucoma filtration surgery if the stimulus to wound healing from tissue rauma were minimised and operative dimensions were accurately controlled. The (193 nm) argon fluoride (ArF) excimer laser has been shown in comeal surgery to perform exceptionally well on both counts, ablating with submicro metre precision and virtually no damage to the adjacent tissues. ${ }^{23}$

Two approaches to glaucoma surgery using the excimer laser at $193 \mathrm{~nm}$ have already been described experimen-

Correspondence to: Bruce Allan, The Lions Eye Institute, 2nd floor, 2 Verdun Street, Nedlands, Western Australia, Australia 6009. tally: partial extemal trabeculectomy, in which ablation of a $2 \mathrm{~mm} \times 0.8 \mathrm{~mm}$ rectangular scleral channel proceeds until increased aqueous efflux arrests progress with removal of the high resistance, endothelial portion of the trabecular meshwork; $;^{4-7}$ and a modified conventional trabeculectomy procedure in which the excimer laser is used to smooth the surfaces beneath a conventionally dissected scleral flap, then to form a sclerostomy and a peripheral iridotomy. ${ }^{8}$ Both these approaches require formal preparatory conjunctival dissection, however, and this in itself is a major element of the tissue rauma inherent in conventional procedures.

Sclerostomies can be formed without conjunctival dissection by a variety of lasers delivered $a b$ interno, either endoscopically or gonioscopically. ${ }^{9-20} \mathrm{Ab}$ interno delivery is not possible with the $193 \mathrm{~nm}$ excimer laser, however, since light at this wavelength is strongly absorbed by the comea and cannot be delivered endoscopically.

An $a b$ externo approach in which conjunctival dissection is avoided has been conceived for the formation of small bore $(\leqslant 500 \mu \mathrm{m})$ sclerostomies using the ArF excimer laser. This utilises a modified open mask to plicate the conjunctiva at the limbus prior to through-andthrough ablation (Fig. 1a). Removal of the mask at the end of the procedure allows the conjunctiva to relax back to its original position, separating the conjunctival wound from the sclerostomy, and allowing a bleb to form (Fig. 1b). The development of a viable modified open mask system for excimer laser sclerostomy formation, and the results of ablation in cadaver pig eyes, are described below.

\section{MATERIALS AND METHODS}

Cadaver pig eyes stored at $4{ }^{\circ} \mathrm{C}$ and used within 12 hours of enucleation were mounted on a vacuum holder. Prototype masks were attached and aligned with the limbus as described above. The eyes were perfused with a constant pressure head of normal saline through an intravitreal cannula and left to equilibrate at $30 \mathrm{mmHg}$ for 5 minutes prior 


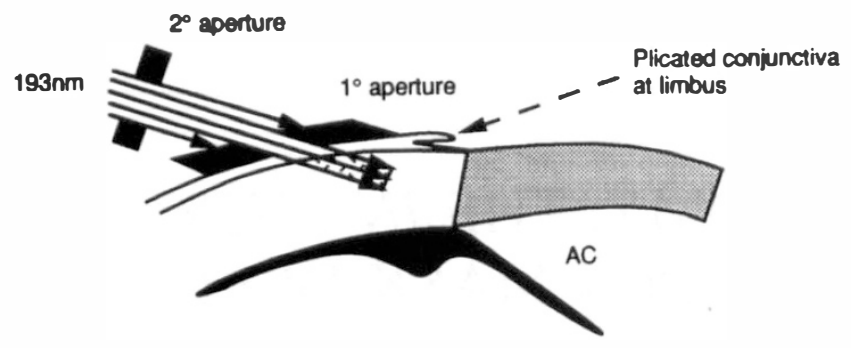

Fig. 1a

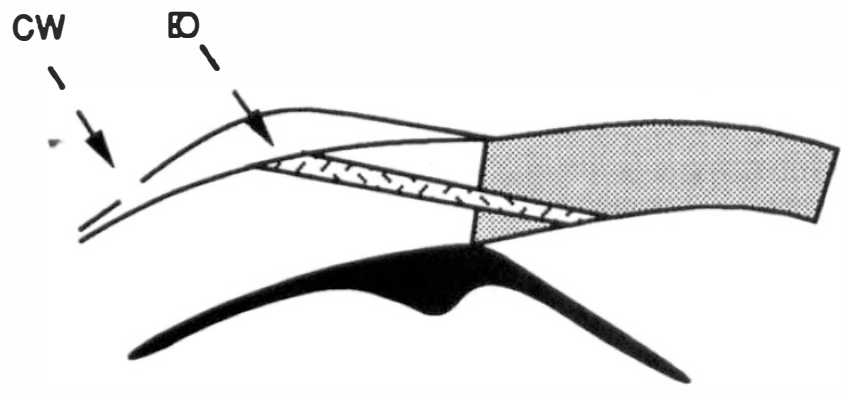

Fig. 1b

Fig. 1. (a) A schematic illustration showing plication of the conjunctiva at the limbus by the main component of the open mask. This fixes the conjunctiva by gentle suction before being hitched forward and stabilised in the definitive position by attachment of a second vacuum component to the cornea (not illustrated). The angle at which the sclerostomy enters the anterior chamber $(A C)$ is controlled by concentric alignment of primary and secondary apertures built into the main component. The primary aperture defines the cross-sectional outline of the sclerostomy. The position of the external ostium is controlled by alignment of the anterior edge of the main component of the mask with the limbus. (b) After ablation is complete and the mask is removed, the conjunctiva relaxes back, clearly separating the small conjunctival wound $(C W)$ from the external ostium (EO) of the sclerostomy.

to ablation. They were then positioned beneath an operating microscope, built into the laser delivery system, with a graticule (indicating the beam centre), the secondary aperture and the primary aperture aligned concentrically.

Using a Questek model $2820 \mathrm{ArF}$ (193 nm) excimer laser with a delivery system configured to produce an even distribution of energy across a $1.5 \mathrm{~mm}$ rotating beam at the mask surface, ablation then proceeded at a fluence per pulse of $400 \mathrm{~mJ} / \mathrm{cm}^{2}$ and a pulse repetition rate of $20 \mathrm{~Hz}$ until penetration had occurred or for a maximum of 5000 pulses. Energy levels were checked prior to each experimental session as previously described. ${ }^{21}$

Intraocular pressure was monitored throughout using a Hewlett-Packard 78905A monitor with a pressure transducer connected to the anterior chamber via a closed fluid interface through a 27 gauge cannula entering opposite the ablation site.

Following ablation, the eyes were immediately perfused with $1 \mathrm{ml} 2.5 \%$ glutaraldehyde via the intracameral cannula. The eyes were then immersed in $2.5 \%$ glutaraldehyde for a minimum of 24 hours before examination under a dissecting microscope. Dissected specimens were dehydrated with serially increased concentrations of alcohol and critical point drying prior to evaporative coating with gold and carbon. Further examination was then performed with a Phillips 505 scanning electron microscope.

The prototype masks were progressively modified to examine the effect of the following air-flow conditions on sclerostomy formation: no air-flow modification, a venturi exhaust system (Fig. 2a), and an en-face jet (Fig. 2b). These modifications were designed to lower and raise the pressure within the ablation channel (i.e. the forming sclerostomy) beneath the mask's primary aperture. The pressure conditions generated were recorded using a water filled U-tube manometer with a rubber cuff on the end of one arm which, when compressed against the inferior aspect of the mask, formed an airtight seal allowing a steady-state measurement of the pressure beneath the primary aperture.

\section{RESULTS}

Three eyes were ablated with no air-flow modification. Constant seepage of aqueous fluid through the sclera into the ablation site was observed. Bright blue/violet fluorescence within the primary aperture was seen throughout ablation, and progress after 5000 pulses was limited in all eyes to a shallow conical indentation (estimated at less than $20 \%$ of scleral thickness) beneath the primary aperture. These specimens were examined under the dissecting microscope only.

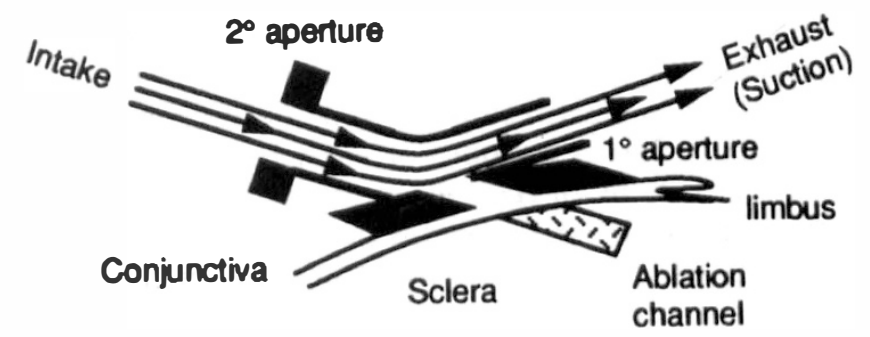

Fig. 2a

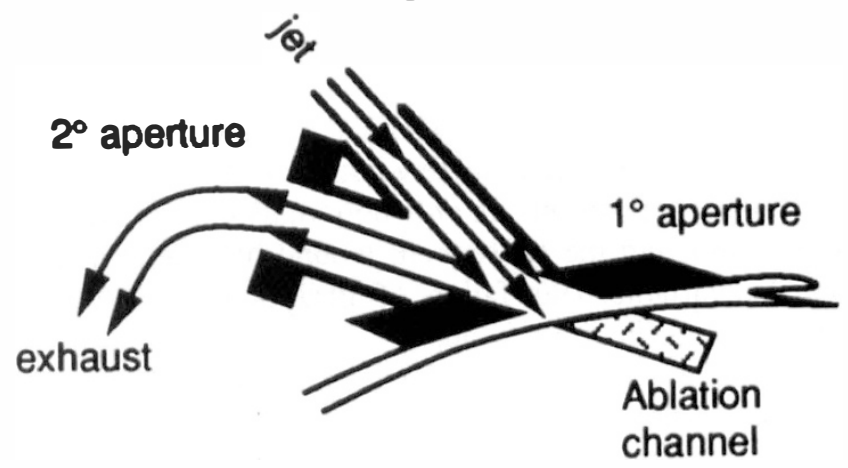

Fig. 2b

Fig. 2. (a) The venturi exhaust system. Air is sucked through the primary aperture and out of the main component of the mask through an exhaust tube. A high-velocity stream of air is thus passed across the primary aperture (see arrows) creating a vacuum in the ablation channel below. The incident beam is directed through the secondary and primary apertures as illustrated in Fig. I(a). (b) The en-face jet system. A jet of sterile air is passed almost directly down through the primary aperture (see arrows) raising the pressure within the ablation channel. Exhaust is through the secondary aperture across which an external current of air is directed to clear ablation products away from the path of the incident beam. 


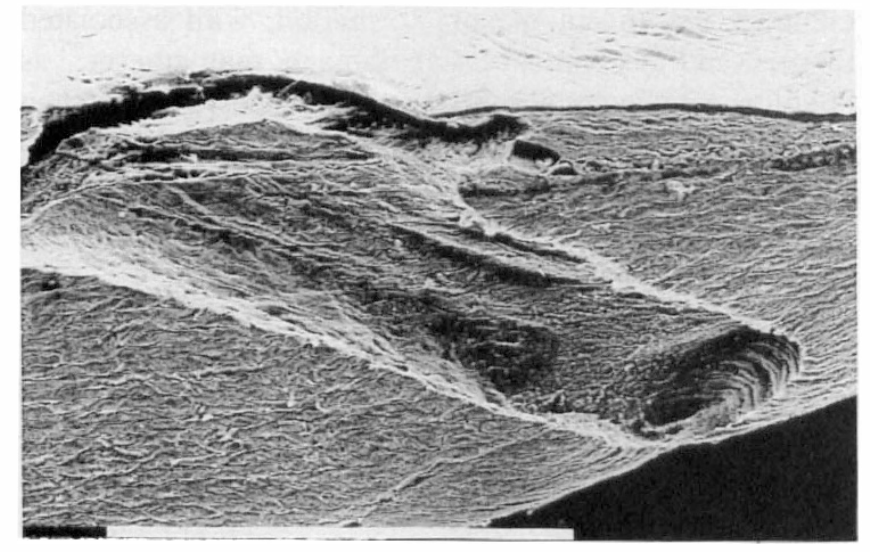

Fig. 3. A $500 \mu \mathrm{m}$ excimer laser sclerostomy formed using the venturi exhaust system, examined in cross-section. Scale bar represents $1 \mathrm{~mm}$.

Eight eyes were ablated using the venturi exhaust system creating a negative pressure of $95 \mathrm{cmH}_{2} \mathrm{O}$ beneath the mask. The primary aperture was $500 \mu \mathrm{m}$ in diameter. Aqueous seepage into the ablation channel was not observed, and initial progress of ablation appeared to be good with a dark hole forming beneath the primary aperture. This became lucent in a characteristic manner as the sclerocorneal junction was passed and transillumination through clear cornea emerged like a new moon gradually becoming full. In three eyes, full-thickness perforation occurred after 4410, 2800 and 3610 pulses. This event was marked by the appearance of a fine fluid ejaculate streaming up the exhaust tube from the primary aperture. In eyes that did not perforate after 5000 pulses, a marked increase in blue/violet fluorescence was noted within the ablation channel at 1000-3000 pulses. Cross-sectional examination of the eye in which perforation occurred at 3610 pulses (Fig. 3) revealed a smooth-walled, cylindrical, $500 \mu \mathrm{m}$ diameter sclerostomy with no apparent damage to the adjacent tissues. At the base, a terraced pattern of transected corneal lamellae was seen stepping down to an eccentrically placed site of full-thickness penetration. Examination of the eyes perforating at 4410 and 2800 pulses from the endothelial side indicated that this site

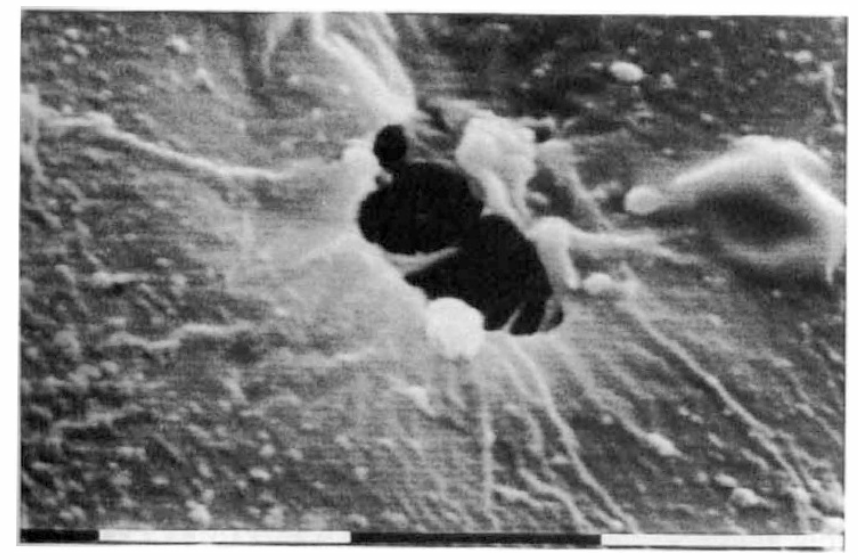

Fig. 4a measured 10-15 $\mu \mathrm{m}$ in its largest dimension (Fig. 4a) and was surrounded by a zone of endothelial loss beneath the main body of the sclerostomy (Fig. 4b). Cross-sectional examination of the remaining eyes revealed sclerostomies similar to that illustrated (Fig. 3), but without a perforation site or a clear terraced lamellar pattern at the base, which included a variable thickness of residual stroma $(<100 \mu \mathrm{m})$ superficial to Descemet's membrane. In one eye ablation appeared to have been arrested much earlier with the transection of an aqueous vein (Fig. 5).

Twenty eyes were ablated with a mask incorporating an en-face air jet. In the first five eyes, a high positive pressure (in excess of $150 \mathrm{mmHg}$ ) was used. The primary aperture was $500 \mu \mathrm{m}$ in diameter. Ablation followed a similar pattern to that observed for the venturi system, but perforation occurred in all five eyes after 2050-2900 pulses (mean 2380) and was marked by the appearance of an air bubble in the anterior chamber. Examination again revealed smooth-walled sclerostomies but with an extensive zone of endothelial damage $(0.5-2 \mathrm{~mm})$ with splits in Descemet's membrane surrounding the internal ostia (Fig. 6).

The minimum en-face jet pressure at which fully penetrating sclerostomies could be obtained was then approximated by ablating five eyes with progressive $10 \mathrm{cmH}_{2} \mathrm{O}(7.4 \mathrm{mmHg})$ increments of pressure beneath the $500 \mu \mathrm{m}$ mask commencing at $20 \mathrm{cmH}_{2} \mathrm{O}$ $(14.8 \mathrm{mmHg})$. All eyes were exposed to 4000 pulses. Examination confirmed that fully penetrating fistulas were obtained where the pressure beneath the mask was $50 \mathrm{cmH}_{2} \mathrm{O}(37 \mathrm{mmHg})$ or greater. Ten eyes were then ablated with a positive pressure of $37 \mathrm{mmHg}$ beneath the mask. The primary aperture was reduced to $300 \mu \mathrm{m}$. Fullthickness penetration occurred in all ten eyes, each exposed to 4000 pulses. The moment of perforation was marked by a sudden change in the retroilluminated base of the ablation channel, with or without the appearance of a small air bubble in the anterior chamber. With perforation, intraocular pressure quickly rose to equilibrate with the en-face jet pressure. Cross-sectional examination of three eyes showed $300 \mu \mathrm{m}$ cylindrical sclerostomies with bases

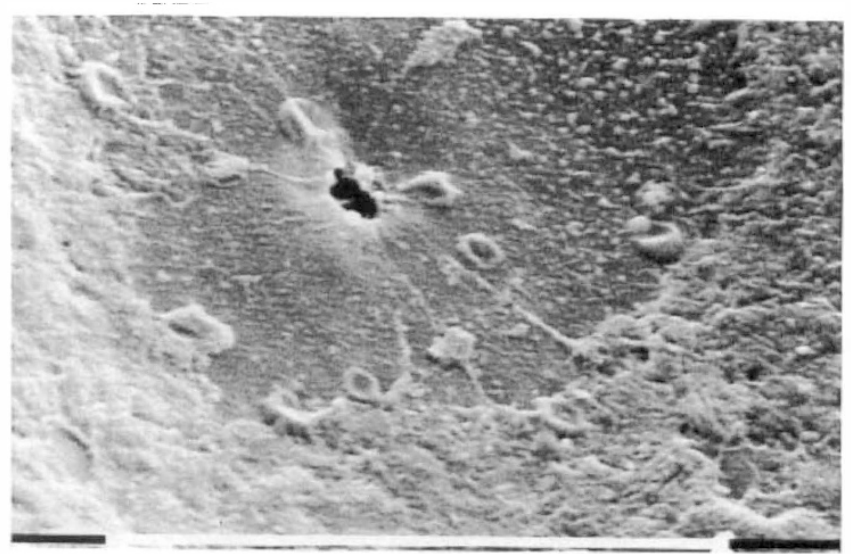

Fig. 4 b

Fig. 4. (a) The small perforation at the base of an excimer laser sclerostomy formed with the venturi exhaust system examined from the endothelial side. Scale bar represents $10 \mu \mathrm{m}$. (b) A lower-point view of the same specimen showing endothelial loss beneath the main portion of the sclerostomy. Scale bar represents $1 \mathrm{~mm}$. 


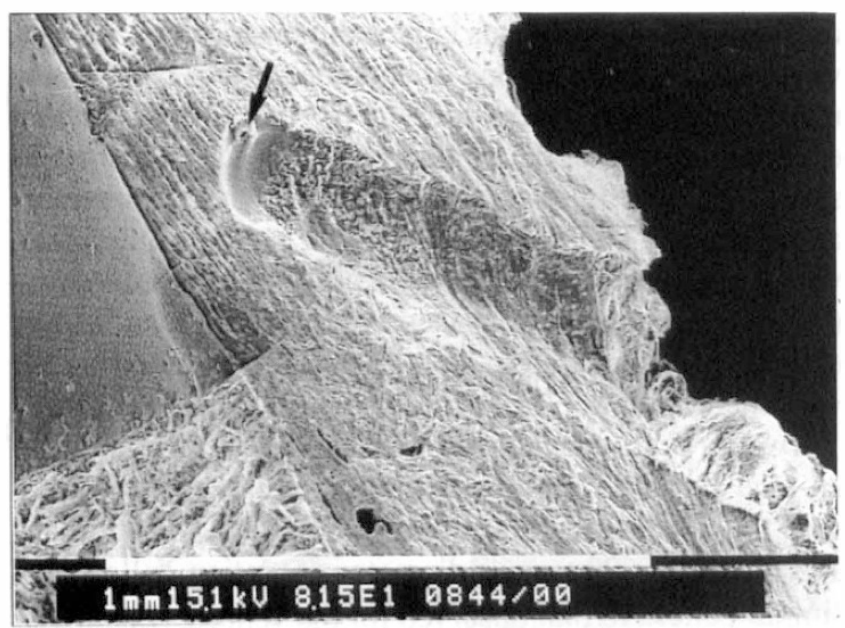

Fig. 5. The base of an ablation channel. Progress of ablation appeared to have been arrested in this case by transection of an aqueous vein (see arrow). Scale bar represents $100 \mu \mathrm{m}$.

truncated obliquely at a variable point by entry into the anterior chamber (Fig. 7a). There was no apparent adjacent tissue damage (Fig. 7b), although a fine fibrillar deposit was consistently seen along the lower edge of the cut section (Fig. 7c). The remaining seven eyes were examined from the endothelial side. Internal ostia were round or oval (Fig. 8) with a smallest diameter varying between 40 and $290 \mu \mathrm{m}$ (mean 188; SD 92). Surrounding endothelial damage was restricted to a maximum radius of $100 \mu \mathrm{m}$. In many areas the endothelium was intact immediately adjacent to the ostium.

\section{DISCUSSION}

The pig eye was used as a test bed because it has similar dimensions to the human eye. In particular, the recess of the anterior chamber angle behind the surgical limbus in the sagittal plane is approximately equivalent.

Ablation parameters were chosen with a view to maximising the speed of sclerostomy completion whilst maintaining the minimal tissue damage zone. A fluence of $400 \mathrm{~mJ} / \mathrm{cm}^{2}$ was selected to produce a relatively high etch depth per pulse without compromising ablation effi-

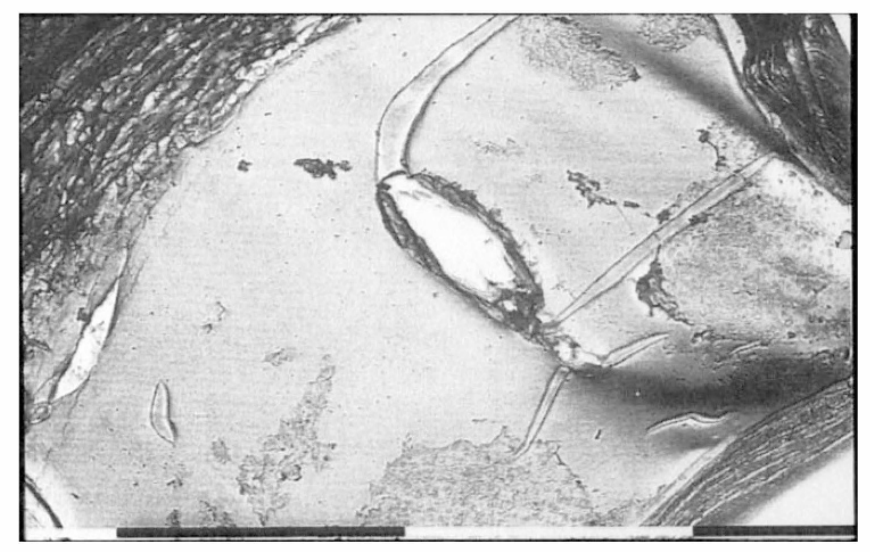

Fig. 6. Extensive endothelial loss and splits in Descemet's membrane surrounding the internal ostium of a sclerostomy formed using a high-pressure $\left(>200 \mathrm{CmH}_{2} \mathrm{O}\right)$ en-face jet. Scale bar represents $1 \mathrm{~mm}$. ciency. ${ }^{22}$ Significant plasma formation, with associated thermal and mechanical tissue damage, may emerge ${ }^{22}$ as ablation efficiency diminishes at fluences greater than $400 \mathrm{~mJ} / \mathrm{cm}^{2}$. Although pulse repetition rates of up to $30 \mathrm{~Hz}^{6}$ have been used in partial external trabeculectomy, thermal damage may begin to accrue ${ }^{23}$ with pulse rates in excess of $20 \mathrm{~Hz}$ at $400 \mathrm{~mJ} / \mathrm{cm}^{2}$.

The immediate conclusion drawn from initial attempts at excimer laser sclerostomy formation was that, unless some provision is made for drying the ablation channel during the procedure, progress is quickly arrested by aqueous seeping in and absorbing the incident radiation.

The venturi exhaust system, in which a jet of dry air is passed over the top of the mask's primary aperture, was designed to encourage evaporation of pooled aqueous by lowering the ambient pressure within the ablation channel, and to conduct vapour away efficiently. This was only partially successful. Slow aqueous pooling during the early stages of ablation appeared to be compensated, but the vacuum later seemed to have the reverse of the desired effect, preventing full-thickness sclerostomy formation by sucking aqueous into the ablation channel.

The opposite approach of raising pressure within the ablation channel using an en-face jet solves this problem. Consistent perforation was obtained where pressure in the ablation channel exceeded intraocular pressure by approximately $10 \mathrm{mmHg}$. Intraocular pressure was maintained at $30 \mathrm{mmHg}$ to simulate the likely conditions in vivo after attachment of a vacuum mask (placement of the prototype vacuum masks was found to raise the intraocular pressure by 6-11 $\mathrm{mmHg}$ ). Use of the minimum enface jet pressure avoids the extensive damage to Descemet's membrane seen where higher pressures are used and the sclerostomy bursts through into the anterior chamber. It also minimises the peak pressure which the eye is exposed to when the sclerostomy enters the anterior chamber and intraocular pressure equilibrates with the air jet. In vivo, there would be a theoretical risk of introducing infection through the air jet at this point; but the sterilising action of $193 \mathrm{~nm}$ irradiation ${ }^{21,24}$ in conjunction with the use of filtered sterile air should minimise this.

For complete penetration in which the internal ostium matches the diameter of the main body of the sclerostomy, ablation for a number of pulses beyond the initial entry is required (since the base of the cylindrical ablation channel is not parallel to the endothelial surface). There might, however, be some advantage in leaving the sclerostomy guarded by a smaller internal ostium to reduce the incidence of complications associated with excessive aqueous outflow. Further studies are in progress to determine the number of additional pulses required for complete penetration and the limits of dimensional reproducibility for both guarded and unguarded sclerostomies produced with this delivery system.

Animal models of filtration surgery ${ }^{25,26}$ indicate that fibroblast proliferation and cicatrisation in the subconjunctival space is the precipitating event in filtration failure rather than internal closure of the drainage fistula 


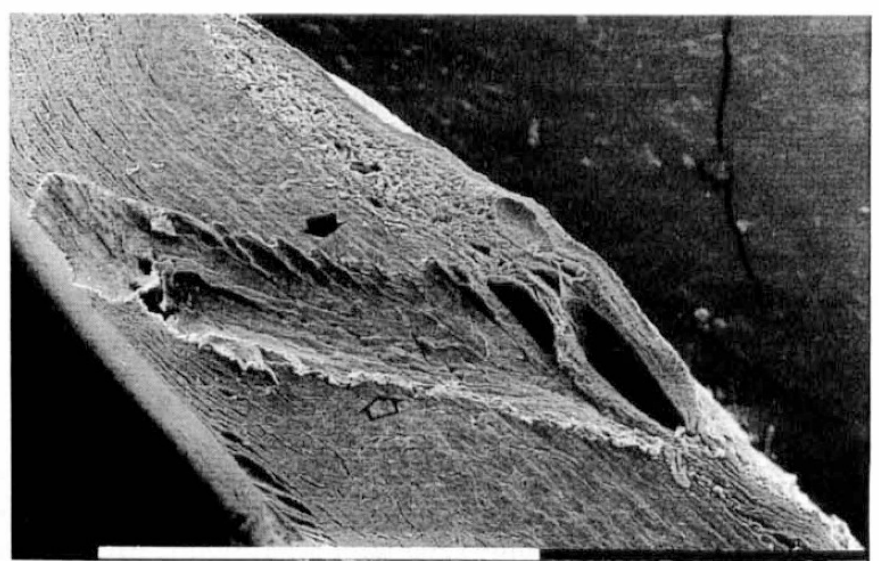

Fig. 7a

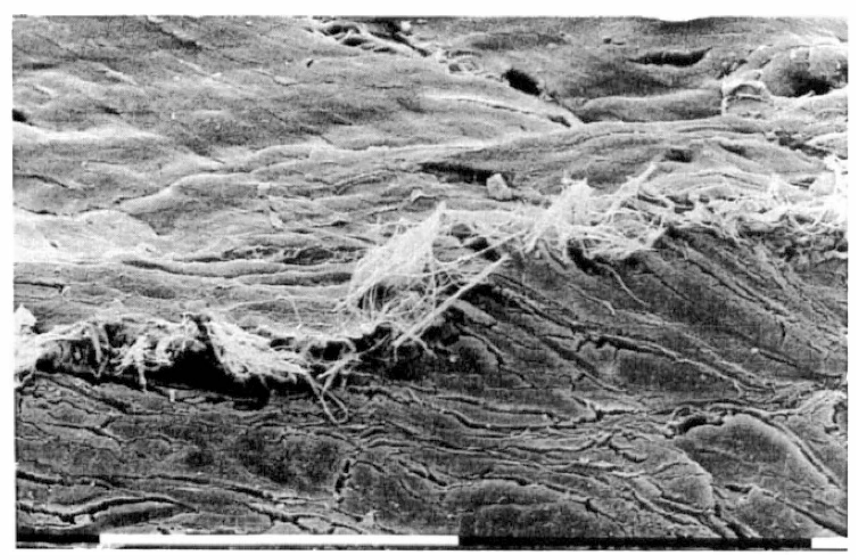

Fig. $7 c$

itself. This would suggest that sclerostomies considerably smaller than those created in conventional full-thickness filtration procedures might be equally effective in maintaining filtration.

Minimising tissue trauma and the stimulus to wound healing may assist in allowing smaller-bore fistulas to remain patent. Using the same contact endoscopic delivery system to create sclerostomies in rabbits with two

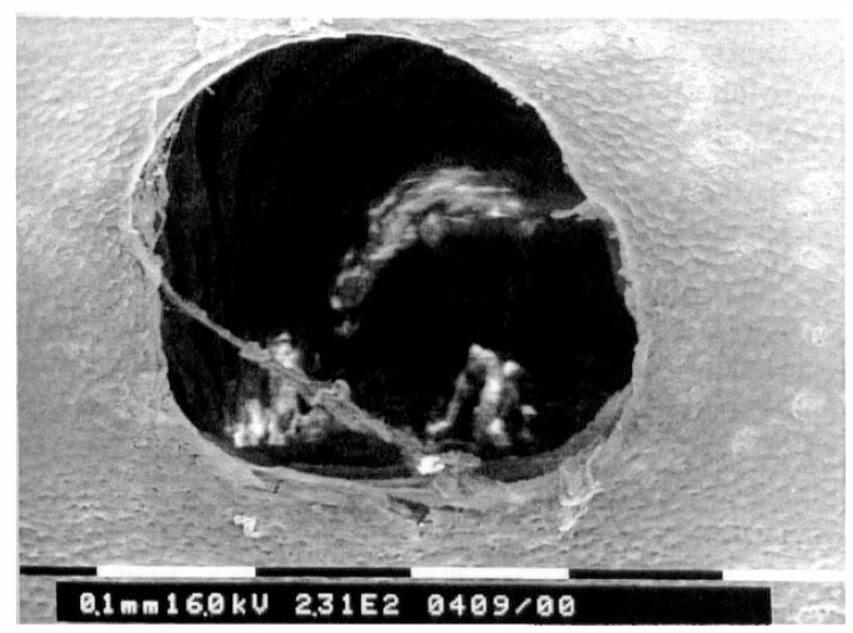

Fig. 8. An excimer laser sclerostomy formed using a lowpressure $(50 \mathrm{c} \mathrm{mH}, O)$ en-face jet examined from the endothelial side, showing minimal disturbance to the adjacent endothelium. Scale bar represents $100 \mu \mathrm{m}$.

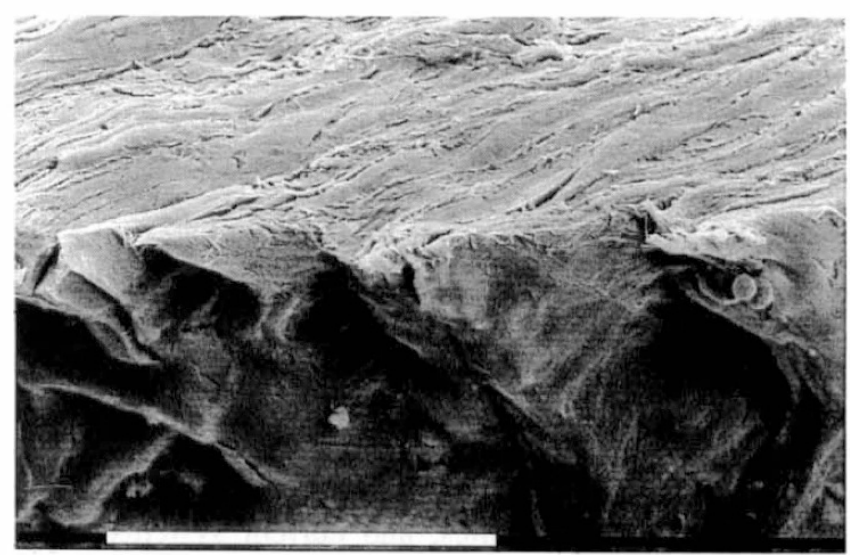

Fig. $7 b$

Fig. 7. (a) A 30) $\mu$ me excimer laser sclerostomy formed using a low-pressure (50) ( $\mathrm{mH}, \mathrm{O})$ en-face jet examined in cross-section. Scale bar represents $1 \mathrm{~mm}$. (b) A high-power view of the middle portion of the upper edge of this specimen (see filled arrow' in (a)) showing the lack of damage to tissues adjacent to the sclerostomy: Scale bar represents $100 \mu \mathrm{m}$. (c) A similar high-power view of the lower edge (see open arrow in (a)) showing a fine fibrillar deposit but again no manifest tissue damage zone. The fibrillar deposit may represent collagen bundles artefactually displaced by the downward sweep of the ra=or blade used to section the specimen.' Scale bar represents $1 \mathrm{~mm}$.

different lasers, Hill et al..$^{27}$ noted that fistulas formed with the mid-infrared erbium laser were significantly more durable than those formed using a continuous wave $\mathrm{Nd}$ :YAG laser with its larger thermal tissue damage zone. Similarly, tistulas created in rabbits with a high-powered argon laser (thermal damage zone $250 \mu \mathrm{m})^{4}$ all closed within 4 days, whereas those created with the $\mathrm{XeCl}$ excimer laser at $308 \mathrm{~nm}$ (thermal damage zone $50-100 \mu \mathrm{m})^{18-20}$ remain patent for up to 4 months. The only clear evidence of damage to the surrounding tissues observed here using the excimer laser at $193 \mathrm{~nm}$ and a mask pressure of $37 \mathrm{mmHg}$ was a variable small $(<100 \mu \mathrm{m})$ zone of endothelial loss about the internal ostia. Open mask delivery ab externo allows free escape of the hot expanding gases created during ablation. This contrasts with current contact endoscopic delivery systems which trap these ablation products within the forming sclerostomy, causing significant secondary thermal and mechanical damage. ${ }^{2 x}$

Early experience of excimer laser sclerostomy in vivo indicates that conjunctival plication to separate the corneal and scleral wounds resulting from through-andthrough ablation works well, and that functional filtration blebs with a self-sealing conjunctival wound can be formed. Although ablation with the ArF excimer laser is non-haemostatic (because of the absence of adjacent coagulative thermal tissue damage), haemostasis is maintained during the procedure by positive pressure tamponade from the en-face jet. and the duration of ablation 
(approximately 4 minutes) exceeds the bleeding time for most of the small vessels transected. Simultaneous coagulation and haemostasis can be obtained in sclerostomy procedures using other lasers, ${ }^{9,15}$ but only at the expense of a relatively large zone of thermal tissue damage.

Laser mechanisms and delivery systems used in sclerostomy procedures have been extensively reviéwed in an earlier paper. ${ }^{29}$ Excimer laser sclerostomy theoretically combines the least traumatic laser with the least traumatic delivery system. Accuracy is similarly optimised. Its use in therapeutic and refractive corneal procedures is likely to continue to propagate the availability of the ArF excimer laser in ophthalmic clinics, and current systems could easily be adapted to accommodate this new procedure, which may eventually offer a convenient, atraumatic and reliable alternative to conventional glaucoma filtration surgery.

Key words: Excimer, Filtration, Glaucoma, Laser, Sclerostomy, Surgery.

\section{REFERENCES}

1. Katz LJ, Spaeth GL. Filtration surgery. In: Ritch R, Shields MB, Krupin T, editors. The glaucomas. St. Louis: CV Mosby, 1989:653-96.

2. Marshall J, Trokel S, Rothery S, Schubert H. An ultrastructural study of corneal incisions induced by an excimer laser at $193 \mathrm{~nm}$. Ophthalmology 1985;57:749-58.

3. Marshall J, Trokel S, Rothery S, Kruger RR. A comparative study of corneal incisions induced by diamond and steel knives and two ultraviolet radiations from an excimer laser. Br J Ophthalmol 1986;70:482-501.

4. Seiler T, Kriegerowski M, Bende T, Wollensak J. Partielle externe trabekulektomie. Klin Monatsbl Augenheilk 1989; 195:216-20.

5. Seiler T, Kriegerowski M, Bende T. Partial external trabeculectomy (PET). Lasers Light Ophthalmol 1989;2:196.

6. Seiler T, Kriegerowski M, Bende T, Wollensak J. Partial trabeculectomy with the excimer laser $(193 \mathrm{~nm})$. Invest Ophthalmol Vis Sci 1988;29 (ARVO Suppl):239.

7. Seiler T, Kriegerowski M, Patmore A, Marshall J. Partial external trabeculectomy with the excimer laser: an experimental investigation of a new treatment for glaucoma. Lasers Light Ophthalmol 1990;3:97-109.

8. Aron-Rosa D, Maden MD, Ganem S, et al. Preliminary study of argon fluoride (193 nm) excimer laser trabeculectomy: scanning electron microscopy at five months. J Cataract Refract Surg 1990;16:617-20.

9. Jaffe GJ, Williams GA, Meiler WF, Radius RL. Ab interno sclerostomy with a high-powered argon endolaser. Am J Ophthalmol 1988;106:391-6.

10. Gaasterland DE, Hennings DR, Boutacoff TA, Bilek C. $A b$ interno and ab externo filtering operations by laser contact surgery. Ophthalmic Surg 1987;18:254-7.

11. Higginbotham EJ, Kao G, Peyman G. Internal sclerostomy with the Nd:YAG contact laser versus thermal sclerostomy in rabbits. Ophthalmology 1988;95:385-90.

12. Javitt JC, O'Connor SS, Wilson RP, Federman JL. Laser sclerostomy ab interno using a continuous wave Nd:YAG laser. Ophthalmic Surg 1989;20:552-6.

13. Latina MA, Dobrogowski MD, March WF, Birngruber R. Laser sclerostomy by pulsed dye laser and goniolens. Arch Ophthalmol 1990;108:1745-50.

14. Hoskins HD, Iwach AG, Drake MV, et al. Subconjunctival THC:YAG laser limbal sclerostomy ab externo in the rabbit. Ophthalmic Surg 1990;21:589-92.

15. Hoskins HD, Iwach AG, Vassiliadis A, et al. Subconjunctival THC:YAG laser thermal sclerostomy. Ophthalmology 1991;98:1394-400.

16. March WF, Koss MC, Gherezghiher T, et al. Histologic study of a neodymium-YAG laser sclerostomy. Arch Ophthalmol 1985;103:860-3.

17. Gherezghiher T, March WF, Koss MC, et al. Neodymium: YAG laser sclerostomy in primates. Arch Ophthalmol 1985; 103:1543-5.

18. Berlin MS, Rajacich G, Duffy M, et al. Excimer laser photoablation in glaucoma filtering surgery. Am J Ophthalmol 1984;103:713-4.

19. Berlin MS, Martinez M, Papaioannou T, Grundfest W. Goniophotoablation: excimer laser glaucoma filtering surgery. Lasers Light Ophthalmol 1988;2:17-24.

20. Muller-Stolzenburg N, von Haebler M, Erb C, Buchwald HJ. Ab interno excimer laser sclerostomy in albino rabbits: influence of a topically applied UV absorber. Invest Ophthalmol Vis Sci 1991;32 (ARVO Suppl):941.

21. Serdarevic O, Darrell RW, Krueger RR, Trokel SL. Excimer laser therapy for experimental candida keratitis. Am J Ophthalmol 1985;99:534-8.

22. Van Saarloos PP, Constable IJ. Bovine corneal stroma ablation rate with $193 \mathrm{~nm}$ excimer laser radiation: quantitative measurement. Refract Corneal Surg 1990;6:424-9.

23. Bende T, Seiler T, Wollensak J. Side effects in excimer corneal surgery. Graefes Arch Clin Exp Ophthalmol 1988;226: 277-80.

24. Gottsch JD, Gilbert ML, Goodman DF. Excimer laser ablative treatment of microbial keratitis. Ophthalmology 1991; 98:146-9.

25. Miller MH, Grierson I, Unger WI, Hitchings RA. Wound healing in an animal model of glaucoma fistulizing surgery in the rabbit. Ophthalmic Surg 1989;20:350-7.

26. Jampel HD, Lorraine JB, McGuigan MD, et al. Cellular proliferation after experimental glaucoma filtration surgery. Arch Ophthalmol 1988;106:89-94.

27. Hill RA, Ozler SA, Baervelt J, et al. Ab interno neodymium:YAG versus erbium:YAG laser sclerostomies in rabbits. Invest Ophthalmol Vis Sci 1991;32 (ARVO Suppl): 388.

28. Berlin M, Martinez M, Peter-Loercher H. Erbium YAG laser sclerostomy: mechanism and histological analysis. Invest Ophthalmol Vis Sci 1991;32 (ARVO Suppl):939.

29. Allan BDS, van Saarloos PP, Cooper RL, Constable IJ. Laser microsclerostomy for primary open angle glaucoma: a review of laser mechanisms and delivery systems. Eye 1992; 6:257-66. 